\title{
Abciximab in the treatment of coronary artery disease
}

Rohan Jayasinghe ${ }^{1}$, Ryan Maxwell ${ }^{2}$, Dale Murdoch ${ }^{2}$

1 Gold Coast Hospital and Griffith University, Queensland, Australia

2 Gold Coast Hospital, Queensland, Australia

\section{Abstract}

Antiplatelet therapy constitutes a cornerstone in the strategies aimed at the effective management of acute coronary syndrome. Abciximab is the oldest and most commonly used intravenous antiplatelet agent in this context, in particular when an invasive strategy is adopted. It is very commonly used in more unstable and high-risk patients. Trials have proven the event-free survival benefits of using abciximab in the right context. This agent also has some adverse outcomes associated with its use that the clinicians need to be well aware of and take precautions against. The comparative cost efficacy with its use too is of significance. There is a growing evidence base on the different ways abciximab is used and the benefits and risks thereof. Since the development and introduction of novel anticoagulants and more potent oral anti-platelet agents, the place of abciximab in the treatment of acute coronary syndrome today needs to be reviewed and clearly defined. This review attempts to study the cross-section of the evidence base to date on the clinical use, efficacy and risks related to the use of abciximab and spotlight the most recent guidelines published by the different global peak bodies to provide a practical overview to the clinician.

\section{Keywords}

Abciximab; Antiplatelet agents; Acute coronary syndromes 


\section{Introduction}

Abciximab is a very commonly used intravenous glycoprotein (GP) IIb/IIIa inhibitor in current cardiovascular therapeutics. GP IIb/IIIa inhibitors are potent intravenous antiplatelet agents that came to prominence in the 1990s for their use in acute coronary syndromes (ACS) and percutaneous coronary intervention (PCI). GP IIb/IIIa inhibitors were created for use as a part of dual anti-platelet strategy in combination with acetyl salicylic acid (aspirin) prior to the wide use of thienopyridines and cyclopentyltriazolopyrimidine agents (clopidogrel, prasugrel, ticagrelor). Abciximab, the first such agent approved by the FDA in 1994, was discovered by Centocor BV and Eli Lilly Incorporated, and has since been distributed under the trade name Reopro ${ }^{\circ}$.

Abciximab is a monoclonal antibody directed against the glycoprotein IIb/IIIa receptor present on platelets and inhibits cross-linking and platelet aggregation. It is created from the fragment antigenbinding $(\mathrm{Fab})$ section of an immunoglobulin and directly targets the platelet membrane where it antagonises the GP IIb/IIIa receptor.

The goals of therapy with this type of agent are to prevent thrombus propagation and re-occlusion in diseased vessels due to excessive platelet reactivity and thereby aid in revascularisation. Abciximab is often used in the setting of PCI as the action of angioplasty and stenting is known to cause endothelial damage and GP IIb/IIIa activation.

\section{Molecular mechanism: the pharmacodynamics and pharmacokinetics of abciximab}

Platelet aggregation is an imperative mechanism by which acute coronary syndrome is triggered and a key target for pharmacotherapy in the treatment of ischaemic heart disease, especially in the acute setting. The surface of the platelet has many mechanisms that contribute to adhesion, aggregation and thrombus formation. One of the most important means by which this occurs is the GP IIb/IIIa receptor, which is regarded as highly platelet specific and present in high frequency $(\sim 80,000$ copies per platelet) on each platelet. When a platelet becomes activated, either by endothelial damage or other similar mechanisms, intracellular pathways cause the GP IIb/IIIa receptor to undergo a conformational change that alters its state from one of low to high affinity [1,2]. Once this takes place, the GP IIb/IIIa receptor is free to bind adhesive molecules such as von Willebrand factor and fibrinogen causing crosslinkage between platelet surfaces and subsequent aggregation. Abciximab works to prevent binding of adhesive molecules to the GP IIb/IIIa receptor, which is the sole mechanism available for the formation of cross-linked platelets and thus prevent further platelet aggregation. When the GP IIb/IIIa receptor is either partially or completely blocked total suppression of platelet aggregation is possible with these agents [3]. Abciximab has also been shown to bind with comparable efficacy to both latent and activated platelet receptors and this further enhances its antiplatelet effect [2].

In order for effective antiplatelet activity to take place $>80 \%$ of target receptors need to be occupied by the GP IIb/IIIa inhibitor. At 50\% occupancy patients may still have close to normal platelet aggregation. High dose bolus abciximab $(0.25 \mathrm{mg} / \mathrm{kg})$ has been shown to cause $\geq 80 \%$ receptor occupancy within 2 hours of administration and therefore complete inhibition of platelet aggregation. After bolus injection abciximab has a short first phase half-life of around 10 minutes with rapidly decreasing plasma levels. A second phase half-life of around 30 minutes follows and this is thought to be due to the initial occupation and binding of GP IIb/IIIa receptors by the bolus dose. The metabolism of abciximab is due to degradation by proteolysis that occurs in the kidney $[2,3]$. The effect of bolus abciximab can be perpetuated by a continuous infusion at $0.125 \mu \mathrm{g} / \mathrm{kg} / \mathrm{min}$ (to a maximum of $10 \mu \mathrm{g} / \mathrm{minute}$ ). 
Upon cessation of abciximab therapy the plasma level drops steeply over 6 hours and thereafter decreases at a much slower rate. Platelet function generally recovers within 48 hours even though low-level receptor blockade can still be present at 10 days and the drug may remain in the circulation for up to 15 days. Recovery of platelet function is independent of the modality of administration.

\section{Indications}

The initial approval for the use of abciximab was for percutaneous coronary intervention (PCI) and was aimed at preventing cardiac ischaemia and its complications during such procedures. Since this time the indication for the use of GP IIb/IIIa inhibitors has expanded to include other acute coronary syndromes and also occasionally, stable ischaemic heart disease. Abciximab was the first such agent used in clinical practice and traditionally is utilised in patients with elevated troponin, high thrombus load on coronary angiography or other high-risk features such as dynamic ECG changes and resistant chest pain. All early clinical trials used these agents in combination with aspirin and unfractionated heparin; therefore today this remains the intended regime of choice when using abciximab.

\section{Efficacy \& evidence from pivotal trials}

During the mid to late 1990s abciximab and the other GP IIb/IIIa inhibitors were subject to extensive study to elicit the true potential benefit of these agents in the treatment of acute coronary syndromes. These early trials utilised GP IIb/IIIa inhibitors as a secondary agent for its potent antiplatelet effect in combination with aspirin and took place before the advent of dual oral antiplatelet therapy with thienopyridines such as clopidogrel. Routine insertion of coronary stents was also not commonplace in the setting of PCI and ACS at this time. These early trials assisted in confirming the theory that potent inhibition of platelet aggregation would lead to improved clinical outcomes and lower mortality.

The EPIC and EPILOG trials were two of the first large clinical trials to investigate the efficacy of abciximab in PCI [4-6]. The EPIC trial administered abciximab as a bolus and 12-hour infusion to patients treated with coronary angioplasty or atherectomy who were deemed high risk for complications of their underlying cardiac disease. This included patients with unstable angina (UA), evolving or recent acute myocardial infarction (AMI) or adverse coronary morphology. The study demonstrated that patients receiving abciximab therapy showed a significant reduction in the incidence of 30-day mortality and morbidity in the form of AMI or need for revascularisation (12.8\% versus $8.3 \%$ with a $35 \%$ relative risk reduction). This benefit was found to extend out to 6 months and 3 years on follow-up. The EPILOG trial extended the use of abciximab therapy to patients with lower risk profiles and was ceased early due to the experimental arms of the study exceeding predetermined superiority levels. This trial demonstrated that the use of abciximab in PCI with low dose or standard dose, weight-adjusted heparin did not carry any significant increase in bleeding complications whilst contributing to superior mortality and morbidity outcomes compared to heparin alone, especially when used in conjunction with early vascular sheath removal and elimination of routine post procedural heparinisation. A combined analysis of the results from the EPIC and EPILOG studies together demonstrated a significant reduction in 30-day death and AMI in patients receiving abciximab $(19.9 \%$ vs. $8.4 \%, \mathrm{p}=0.008)$ and this benefit persisted out to 6 months.

The EPISTENT study looked into the comparative efficacy of abciximab in the setting of coronary intervention with stenting and coronary intervention with balloon angioplasty alone in comparison to stenting with placebo. There were significant reductions in the 30-day composite of death, revascularisation and MI in the abciximab arms [7]. This study proved the case for the use of abciximab with stenting for superior event-free survival in patients undergoing PCI. 
The CAPTURE trial extended the potential value of GP IIb/IIIa inhibitors by demonstrating its efficacy in patients with refractory unstable angina [5,8]. Patients receiving abciximab had lower rates of AMI prior to and during percutaneous trans luminal coronary angioplasty (PTCA) and also achieved the primary composite endpoint of decreased all-cause mortality, AMI or revascularisation at 30 days ( $11.3 \%$ vs. $15.9 \%, \mathrm{p}=0.012$ ). The CAPTURE trial demonstrated that the use of 18 to 24 -hour pre-procedural abciximab infusion was effective at stabilising patients with ACS whilst improving the safety of PCTA and reducing early ischaemic events.

A meta-analysis of the RAPPORT, ADMIRAL, ISAR-2, CADILLAC and ACE trials was performed to investigate the efficacy of abciximab in PCI and stenting fo AMI [9]. This meta-analysis showed that abciximab was effective in reducing early mortality at 30 days compared to placebo (2.4\% vs. 3.4\%) and that this benefit extended out to 6 and 12 months on follow up. Rates of re-infarction with abciximab therapy were also lower at 30 days (1.0\% vs. $1.9 \%)$ and there was no significant increase in bleeding with the use of a GP IIb/IIIa inhibitor.

In the year 2000 a pooled analysis of 21 trials was performed to evaluate the use of GP IIb/IIIa inhibitors in a variety of clinical settings including ST segment elevation myocardial infarction (STEMI), NonST segment elevation myocardial infarction (NSTEMI) and ACS undergoing PCI [10]. This analysis incorporated close to 50,000 patients who had been enrolled in randomised control trials up until that time. GP IIb/IIIa inhibitors were shown to significantly reduce the combined endpoint of 30-day death, nonfatal AMI or urgent revascularisation in patients with STEMI (3.9\% vs. 7.8\%), NSTEMI (11.4\% vs. $12.8 \%)$, and collectively those undergoing PCI (7.8\% vs. $11.6 \%)$.

The BRAVE-3 trial was aimed at determining the efficacy of abciximab therapy prior to PCI in patients who had received dual oral antiplatelet therapy with aspirin and a loading dose of $600 \mathrm{mg}$ clopidogrel [11]. Early positive trials in the use of GP IIb/IIIa inhibitors were prior to routine loading of clopidogrel so this study was intended to address abciximab use in conjunction with the now commonplace use of thienopyridines in patients receiving PCI. In this trial 800 patients who presented within 24 hours of STEMI were loaded with clopidogrel and transferred to an intensive care unit (ICU) prior to primary PCI. In ICU the patients were randomised to either intravenous abciximab infusion or placebo in a double-blinded manner and treated for 12 hours prior to PCI. Results demonstrated no significant change in infarct size as measured by single-photon emission computed tomography and there was no improvement in the rates of 30 day mortality or recurrent AMI. Both study-groups had equivalent rates of bleeding complications. The main detractor from this study was the upstream (prior to catheterisation) use of abciximab, which (as discussed later) has been shown to be of questionable benefit when compared to downstream administration (within the cardiac catheter laboratory).

\section{Use of glycoprotein IIb/IIla inhibitors in conjunction with thrombolysis}

The role of GP IIb/IIIa inhibitor treatment in conjunction with thrombolysis in STEMI was investigated prior to the routine use of dual oral anti-platelet therapy with two large randomised trials, GUSTO $\mathrm{V}$ and ASSENT-3.

GUSTO V was a study involving 16,588 patients randomised to either full-dose thrombolysis with reteplase versus half-dose reteplase and full dose abciximab therapy [12]. Overall results showed no statistical difference in the primary end point of 30-day mortality. Patients who received combination treatment did have a lower incidence of re-infarction and recurrent ischaemia within 7 days but this was at the cost of more bleeding complications. Patients from the combination arm had significantly more thrombocytopaenia, bleeding and requirement for transfusion $(\mathrm{p}<0.0001)$, this was particularly relevant in patients over 75 years of age. 
ASSENT-3 was a similar large trial, which published comparable results around the same time as GUSTO V [13]. It involved the randomisation of 6095 patients to one of three groups:

- full-dose tenecteplase and therapeutic dose enoxaparin;

- full-dose tenecteplase and unfractionated heparin;

- half-dose tenecteplase, unfractionated heparin and 12-hour infusion of abciximab.

The investigators found no significant difference in the 30-day mortality rates between the three arms, but there was an increased risk of bleeding and transfusion requirement in the abciximab arm. Similar to GUSTO V, this trial also demonstrated increased risk of overall bleeding specifically in the abciximab arm with a further increased propensity for complications in patients over 75 years of age, including intracranial haemorrhage.

The more recent (2007) FINESSE study compared primary PCI with abciximab in the catheterisation laboratory, facilitated PCI with upstream abciximab and facilitated PCI with upstream abciximab and reteplase [14]. 1693 patients were randomised to the three arms of the study. Results showed that combination therapy did not demonstrate any clinical benefit in all-cause mortality or complications from AMI. TIMI major and minor bleeding was significantly increased in the two arms of facilitated PCI compared to primary PCI ( $14.5 \%$ vs. $10.1 \%$ vs. $6.9 \%$, respectively).

Given the data currently available, routine use of GP IIb/IIIa inhibitors in conjunction with thrombolysis is not recommended and may lead to significant bleeding complications, especially in the elderly population.

\section{Complications and safety}

The major safety issues that surround abciximab are with regards to its associated risk of thrombocytopaenia, significant bleeding and possible drug allergy.

\section{Thrombocytopaenia}

The finding of a low platelet count with the use of GP IIb/IIIa inhibitors is a common adverse event and usually presents in one of the two following ways:

- pseudothrombocytopaenia due to testing artefact or

- true thrombocytopaenia as an immune mediated phenomenon.

Pseudothrombocytopaenia refers to a laboratory artefact due to the clumping of platelets usually in the presence of EDTA anti-coagulant common to the blood tubes used during collection. In a review of four large trials involving the use of abciximab the incidence of pseudothrombocytopaenia was found to be $2 \%$ overall which accounted for over one third (36\%) of all thrombocytopaenia involved in the use of abciximab [15]. Patients diagnosed with pseudothrombocytopaenia were found to have no associated adverse clinical outcomes.

A clear association has been found between the use of all GP IIb/IIIa inhibitors and clinically significant true thrombocytopaenia. This adverse outcome, which at times may be quite profound, usually occurs within the first 24 hours but has been noted to occur as early as 30 minutes to several hours post administration [16-19]. This phenomenon has been found to be independent of heparin induced thrombocytopaenia (HIT) that caused early contention as both agents are commonly used in conjunction. Thrombocytopaenia from GP IIb/IIIa inhibitors has been found to be rapid and at times severe in nature with platelet counts under 30,000 per $\mu$ l whilst HIT is usually of more slow progression and onset with a less significant drop in platelet numbers [20].

The mechanism of this rapid fall in platelets is thought to be auto-immune in nature and related to antibodies targeting the murine peptide sequences incorporated into the Fab fragment of the monoclonal antibody abciximab once it has interacted with the GP IIb/IIIa receptor [21]. 
A pooled analysis was performed to evaluate the significance of thrombocytopaenia associated with the use of GP IIb/IIIa inhibitors. Eight randomised control trials were reviewed and it was found that abciximab increased the incidence of both mild (4.2\% vs. $2 \%)$ and severe thrombocytopaenia ( $1 \%$ vs. $0.4 \%)$ as compared to placebo [18].

The TARGET trial revealed that thrombocytopaenia was an adverse event more common to abciximab (2.4\%) than tirofiban (0.5\%) [19]. It also revealed that those patients who suffered from thrombocytopaenia had an increased incidence of severe bleeding (5.1 versus $0.7 \%)$, required more blood transfusion (6.1 versus $1.4 \%$ ) and suffered higher rates of 30-day mortality, myocardial infarction or needed more revascularisation $(12.2 \%$ vs. $6.6 \%)$.

Management of thrombocytopaenia associated with GP IIb/IIIa inhibitors requires regular monitoring of platelet levels and thereby earlier detection. It is reasonable to obtain platelet counts on such patients prior to treatment; 2-4 hours post bolus injection, daily during therapy and prior to discharge [17]. If a drop in the platelet count of $>75 \%$ of pre-treatment level or below 100,000 per $\mu l$ is documented then further management should involve:

- ruling out pseudothrombocytopaenia with a peripheral blood smear looking for platelet clumping;

- cessation of the GP IIb/IIIa infusion;

- exclusion of other possible cause of low platelet count including HIT;

- platelet transfusion may be considered in the presence of severe bleeding, platelet count $<10,000$ per $\mu l$ or if an emergency invasive procedure is required.

Re-administration of abciximab to patients with documented GP IIb/IIIa induced thrombocytopaenia is not recommended as it has been found to carry a high risk of recurrent and often more significant thrombocytopenia. An incidence around $2.4 \%$ of platelet counts below 20,000 per $\mu \mathrm{l}$ was noted on one study and it was as high as $12 \%$ if the second exposure was within 2 weeks from the initial administration $[22,23]$.

\section{Bleeding}

Given the nature of its antiplatelet action and with its utilisation most commonly in the setting of other anticoagulant agents, bleeding is a significant concern with the use of GP IIb/IIIa inhibitors.

Early studies in the use of GP IIb/IIIa inhibitors, prior to the introduction of dual oral antiplatelet therapy, had conflicting results with regards to incidence of bleeding in comparison to placebo. Some studies showed a higher incidence of statistically and clinically significant bleeding [24,25] while others were more equivocal [26-28]. Overall these randomised control trials demonstrated that abciximab can increase the bleeding risk by up to $7 \%$ in comparison to placebo.

The ISAR-REACT 2 trial was a study involving 2022 patients who received pre-treatment with aspirin and $600 \mathrm{mg}$ clopidogrel prior to PCI[29]. This study did not reveal a statistically significant difference in the rates of bleeding between patients receiving abciximab versus placebo (4.5\% and $4.0 \%$ respectively).

With regards to the specific complication of intracerebral haemorrhage (ICH), a pooled analysis of 14 randomised trials was performed looking at 28,000 patients who either received a GP IIb/IIIa inhibitor or placebo [30]. The incidence of ICH with the use of GP IIb/IIIa inhibitor and heparin was not statistically different to heparin together with placebo $(0.12 \%$ vs. $0.09 \%$, odds ratio 1.3$)$ and there was no difference between the use of a GP IIb/IIIa inhibitor or heparin as the sole agent $(0.07 \%$ vs. $0.06 \%)$.

\section{Allergy}

Although an antibody response to the monoclonal abciximab has been theorised to cause a sub type of immune mediated thrombocytopaenia in clinical use, there has been no increased evidence of allergic reactions or anaphylaxis in its use whether as single bolus or recurrent infusions [22,23]. 


\section{Safety related to coronary artery bypass graft (CABG) surgery}

Emergency CABG after recent infusion of abciximab with PCI has been associated with increased risk of bleeding complications and increased mortality [31]. This risk is substantially increased if the drug is discontinued within 6 hours of the operation and is thought to be due to the extended antiplatelet effect elicited by abciximab. The risk of peri-operative complications seems largely dependent on the interval between abciximab cessation and surgery. Studies involving patients receiving CABG more than 2-hours post abciximab infusion were not found to have a significant increase in blood transfusion although requirement for platelet infusion was more common [32-34]. Evidence of significant bleeding events become much more prominent with emergency CABG operations occurring under 24 hours post cessation of abciximab. Patients were found to need up to 6 units of packed red cells and 20-30 units of platelets and 4-8 units of fresh frozen plasma peri-operatively [35,36]. These studies have delivered differing results with regards to the increase in peri-operative mortality.

In summary, recent abciximab infusion is not a contra-indication to urgent CABG but measures should be taken to delay the operation where possible. If emergency bypass surgery is required within 12-24 hours of abciximab infusion, a high level of caution should be exercised and supportive measures should be put in place to prevent or treat excessive bleeding.

\section{Comparison with eptifibatide}

Eptifibatide is a synthetic cyclic heptapeptide antagonist of GP IIb/IIIa which was discovered by COR Therapeutics and Schering Plough and approved by the FDA four years after abciximab, in 1998. Eptifibatide is produced under the trade name Integrilin ${ }^{\circledR}$ and was discovered in the venom of the American southeastern pygmy rattlesnake during a search of snake venoms with the potential to inhibit the GP IIb/IIIa receptor. Eptifibatide is used in patients undergoing PCI in the setting of ACS and sometimes for stable coronary disease. It is used to reduce the risk of morbidity and mortality due to thrombotic complications.

As opposed to abciximab, eptifibatide has a much lower affinity in binding the GP IIb/IIIa receptor and thus has a much shorter plasma half-life of approximately 1.5 to 2 hours. Due to this increased clearance, restoration of normal haemostatic function can be obtained within 3-4 hours of infusion cessation. Eptifibatide is primarily cleared by the kidneys ( 98\%) and thus is relatively contra-indicated in renal impairment. It may still be utilised in this subset of patients but requires halving of dosage in moderate to severe renal impairment (creatinine clearance $<50 \mathrm{ml} / \mathrm{min}$ using the Cockcroft-Gault formula) and is contra-indicated in haemodialysis patients due to lack of trial data.

Due to the similar mechanism of action between abciximab and eptifibatide (and also the similar nonpeptide inhibitor tirofiban), many trials have looked for variance between the agents with regards to patient outcome and adverse effects.

In 2010, a retrospective analysis of the Swedish Coronary Angiography and Angioplasty Registry (SCAAR) was performed involving 11,479 patients between 2004-2007 who underwent primary PCI and received either abciximab or eptifibatide. The primary endpoint was death or myocardial infarction during 1-year follow-up in an effort to test non-inferiority of the newer agent, eptifibatide. The results of the multivariate analysis confirmed non-inferiority in the primary endpoint as well as the secondary endpoints of death and MI individually, thus suggesting that either drug is appropriate in this setting [37].

That same year the results of the Eptifibatide versus Abciximab (EVA-AMI) Trial also concluded eptifibatide was as effective as abciximab as an adjunct to primary PCI with respect to ST segment resolution [38]. Two separate meta-analyses of randomised trials were completed in 2009 comparing the use of abciximab versus small-molecule GP IIb/IIIa inhibitors (either tirofiban or eptifibatide) in STEMI patients 
undergoing PCI $[39,40]$. Both analyses showed no significant difference in clinical outcomes or complications. There was no statistically significant difference in rates of 30-days mortality, re-infarction or major bleeding. These results were sustained up to 8 months post procedure.

Specifically with regards to rates of stent thrombosis post PCI, results from the HORIZONS-AMI Trial were presented in 2009 [41] which revealed no significant difference between the two GP IIb/IIIa inhibitors up to 1 year of follow up, suggesting that eptifibatide has equivalent incidence of stent thrombosis compared to abciximab ( $3.6 \%$ versus $2.8 \%, \mathrm{p}=0.93$ ).

Given the above studies, either agent is considered acceptable in the invasive management of acute coronary syndromes and has been proven to have similar rates of positive outcome and complications. Being the first glycoprotein IIb/IIIa inhibitor made available for clinical use, abciximab has the largest volume of data related to its safety and efficacy (including in those with renal impairment). However a cost-analysis published by Jayasinghe et al. revealed that eptifibatide may be significantly more economical than abciximab when used in the setting of invasive management of STEMI [42].

\section{Comparison with bivalirudin}

Bivalirudin is a novel anticoagulant which has recently begun to feature prominently in global cardiac guidelines due to recent study data. It is a potent and highly specific short synthetic peptide that is a reversible direct inhibitor of thrombin. Bivalirudin has a quick onset of action and short half-life and does not carry the risk of thrombocytopaenia. Given that it does not bind plasma proteins or red cells, bivalirudin has a predictable and reproducible antithrombotic response, which makes it a very suitable alternative to heparin therapy. Bivalirudin has been the subject of many recent studies and analyses with regards to its use in acute coronary syndromes, usually in comparison to heparin +/- GP IIb/IIIa inhibitors.

HORIZONS-AMI was a large prospective, multicentre randomised trial in STEMI patients undergoing primary PCI comparing bivalirudin monotherapy to heparin plus GP IIb/IIIa inhibitor [43,-45]. It showed a significant decrease in the incidence of net adverse events ( $9.2 \%$ vs. $12.1 \%$ ) and major bleeding ( $4.9 \%$ vs. $8.4 \%$ ) in the bivalirudin group at 30 days, and these benefits were shown to persist out to 2 years of follow-up. The rate of early stent thrombosis ( $<24$ hours) was increased by $1 \%$ with bivalirudin alone $(\mathrm{p}<0.05)$ but the overall rate was similar on further follow-up, from 30 days to 2 years.

A pooled analysis of two similar trials (ACUITY \& ISAR-REACT 4) in the treatment of non-ST segment elevation myocardial infarction revealed similar results of no significant rise of net adverse events at 30 days and that bivalirudin alone was superior in reducing the incidence of bleeding events when compared to the combination heparin and GP IIb/IIIa strategy [46].

The REPLACE-2 multicentre randomised trial also showed significant reduction in major bleeding with bivalirudin monotherapy versus heparin plus GP IIb/IIIa inhibitor (2.4 vs. $4.1 \%$ ) and also a $24 \%$ risk reduction of death that sustained up to 12 months [47].

Due to recent positive results in the use of bivalirudin for both STEMI and NSTEMI coronary syndromes it is now recommended in both the European Cardiac Society (ESC) and American College of Cardiology/American Heart Association (ACC/AHA) guidelines for use as a sole anticoagulation agent with PCI. It may prove especially useful in those with elevated bleeding risk and the option of bailout with GP IIb/IIIa inhibitors in high-risk patients still remains a safe option with this strategy.

\section{Intracoronary vs. intravenous administration}

Some debate has surrounded the intra-coronary use of abciximab and other GP IIb/IIIa inhibitors versus the standard of care, which is intravenous administration. Early trials using these two methods were of high quality but small in nature and demonstrated varied results. 
Two meta-analyses were published in 2012 with differing results but came to an agreement on the suspected role of intra-coronary GP IIb/IIIa inhibitors. The first study by Shimada et al. showed a significant reduction in mortality with intra-coronary use of abciximab $(1.5 \%$ vs. $3.6 \%, p=0.04)$ [48]. In comparison De Luca et al. completed a meta-analysis of 8 randomised control trials that revealed significant improvement in myocardial perfusion but with no significant benefit to mortality [49].

The recently published AIDA STEMI study was the first large prospective randomised control trial to compare intracoronary administration and systemic administration of GP IIb/IIIa in STEMI. This trial looked at 2065 patients undergoing PCI for STEMI. Results of the study showed no significant difference in the primary endpoint, the composite of mortality, new MI and new heart failure at 90 days [50]. Given the research to date, intracoronary administration of GP IIb/IIIa inhibitors remains a viable alternative in the treatment of acute coronary syndromes but has not yet been proven superior to systemic administration. Theoretically intra-coronary administration may perhaps be safer than systemic administration in the setting of high bleeding-risk.

\begin{tabular}{|c|c|c|c|}
\hline TRIAL & Method & Outcomes & References \\
\hline $\begin{array}{l}\text { EPIC } \\
1995 \\
n=1362\end{array}$ & $\begin{array}{l}\text { Abciximab therapy vs placebo } \\
\text { in high risk patients undergoing } \\
\text { coronary intervention }\end{array}$ & $\begin{array}{l}\text { Abciximab reduced } 30 \text { day death and recurrent AMI } \\
\text { Results trended out to } 6 \text { months follow-up }\end{array}$ & {$[4,5]$} \\
\hline $\begin{array}{l}\text { EPILOG } \\
1998 \\
n=2792\end{array}$ & $\begin{array}{l}\text { Abciximab plus either standard } \\
\text { or low dose heparin vs. standard } \\
\text { dose heparin and placebo during } \\
\text { coronary intervention }\end{array}$ & $\begin{array}{l}\text { Significant reduction in } 30 \text { day mortality and } \mathrm{AMI} \\
\text { requiring trial to be stopped } \\
\text { Bleeding incidence equivalent to placebo }\end{array}$ & {$[5,6]$} \\
\hline $\begin{array}{l}\text { EPISTENT } \\
1998 \\
\mathrm{n}=2399\end{array}$ & $\begin{array}{l}\text { Stenting and placebo vs stenting } \\
\text { and abciximab vs. angioplasty } \\
\text { and abciximab during coronary } \\
\text { intervention }\end{array}$ & $\begin{array}{l}\text { Significant decrease in death and large AMI with the } \\
\text { use of abciximab } \\
\text { Balloon angioplasty with abciximab is safer than } \\
\text { stenting without abciximab } \\
\text { Less bleeding with the use of abciximab }\end{array}$ & [7] \\
\hline $\begin{array}{l}\text { CAPTURE } \\
1997 \\
\mathrm{n}=1265\end{array}$ & $\begin{array}{l}\text { Bolus and infusion abciximab vs. } \\
\text { placebo for refractory unstable } \\
\text { angina going for PTCA }\end{array}$ & $\begin{array}{l}\text { Trial stopped early due to positive results } \\
\text { Significantly reduced } 30 \text { day mortality, AMI, } \\
\text { revascularisation } \\
\text { Low rates of bleeding }\end{array}$ & {$[5,8]$} \\
\hline $\begin{array}{l}\text { BRAVE-3 } \\
2009 \\
n=800\end{array}$ & $\begin{array}{l}\text { Upstream abciximab vs. placebo in } \\
\text { STEMI, used in conjunction with } \\
\text { dual antiplatelet therapy }\end{array}$ & $\begin{array}{l}\text { No reduction in infarct size on sestamibi scanning } \\
\text { with addition of abciximab to aspirin plus } \\
\text { clopidogrel }\end{array}$ & [11] \\
\hline $\begin{array}{l}\text { GUSTO V } \\
2001 \\
\mathrm{n}=16,588\end{array}$ & $\begin{array}{l}\text { Half-dose reteplase and abciximab } \\
\text { vs. full-dose reteplase in STEMI }\end{array}$ & $\begin{array}{l}\text { Non-inferiority of reteplase and abciximab but no } \\
\text { significant reduction in mortality }\end{array}$ & [12] \\
\hline $\begin{array}{l}\text { ASSENT-3 } \\
2001 \\
\mathrm{n}=6095\end{array}$ & $\begin{array}{l}\text { Full-dose tenecteplase and } \\
\text { enoxaparin vs. half-dose tenecteplase } \\
\text { and UFH and abciximab vs. full-dose } \\
\text { tenecteplase and UFH in AMI }\end{array}$ & $\begin{array}{l}\text { Reduced complications of AMI with both } \\
\text { enoxaparin and abciximab regimes } \\
\text { Enoxaparin and tenecteplase demonstrated the } \\
\text { most significant decrease in } 30 \text { days mortality }\end{array}$ & [13] \\
\hline $\begin{array}{l}\text { FINESSE } \\
2008 \\
n=2452\end{array}$ & $\begin{array}{l}\text { Reduced dose reteplase and } \\
\text { abciximab vs. abciximab alone vs. } \\
\text { placebo in STEMI with delay to } \\
\mathrm{PCI}\end{array}$ & $\begin{array}{l}\text { No significant difference in outcome between study } \\
\text { arms } \\
\text { Trend toward better outcome with abciximab and } \\
\text { reteplase in anterior MI }\end{array}$ & [14] \\
\hline $\begin{array}{l}\text { TARGET } \\
2001 \\
\mathrm{n}=5308\end{array}$ & $\begin{array}{l}\text { Abciximab vs. tirofiban in patients } \\
\text { receiving } \mathrm{PCl} \text { and stenting }\end{array}$ & $\begin{array}{l}\text { Superiority of abciximab with decreased } 30 \text { day } \\
\text { mortality, MI or revascularisation vs tirofiban } \\
\text { More significant thrombocytopaenia with abciximab } \\
\text { than tirofiban with associated increase in bleeding }\end{array}$ & [19] \\
\hline \multicolumn{4}{|c|}{ continues } \\
\hline
\end{tabular}


$>$ follows

\begin{tabular}{|c|c|c|c|}
\hline $\begin{array}{l}\text { ISAR-REACT } 2 \\
2006 \\
n=2022\end{array}$ & $\begin{array}{l}\text { Abciximab vs. placebo in NSTEMI } \\
\text { undergoing PCI with dual } \\
\text { antiplatelet therapy on board }\end{array}$ & $\begin{array}{l}\text { Significant reduction in } 30 \text { day mortality, } \mathrm{MI} \text { or } \\
\text { revascularisation with abciximab in patients with an } \\
\text { elevated troponin level } \\
\text { No significant difference in bleeding }\end{array}$ & [29] \\
\hline $\begin{array}{l}\text { EVA-AMI } \\
2010 \\
n=427\end{array}$ & $\begin{array}{l}\text { Eptifibatide vs abciximab therapy } \\
\text { in STEMI planned for } \mathrm{PCl}\end{array}$ & $\begin{array}{l}\text { Non-inferiority of eptifibatide compared to } \\
\text { abciximab with regards to ST segment resolution }\end{array}$ & [38] \\
\hline $\begin{array}{l}\text { HORIZONS- } \\
\text { AMI } \\
2008 \\
n=3602\end{array}$ & $\begin{array}{l}\text { Bivalirudin vs. heparin and GP } \\
\text { Ilb/IIla inhibitor (abciximab } \\
\text { or eptifibatide) in STEMI } \\
\text { receiving PCI }\end{array}$ & $\begin{array}{l}\text { Significantly less major bleeding and mortality at } 30 \\
\text { days with the use of bivalirudin }\end{array}$ & {$[41,43,44,45]$} \\
\hline $\begin{array}{l}\text { REPLACE-2 } \\
2003 \\
n=6010\end{array}$ & $\begin{array}{l}\text { Bivalirudin with provisional GP IIb/ } \\
\text { IIla inhibitor vs. low-dose UFH and } \\
\text { GP IIb/IIla inhibitor in urgent or } \\
\text { elective PCI }\end{array}$ & $\begin{array}{l}\text { Bivalirudin proved superior to heparin alone in } \\
\text { primary endpoints of mortality } \\
\text { Less bleeding with bivalirudin and provisional GP } \\
\text { IIb/IIla inhibitor } \\
\text { Non-inferiority of bivalirudin vs. UFH \& GP IIb/IIla } \\
\text { inhibitor }\end{array}$ & [47] \\
\hline $\begin{array}{l}\text { AIDA STEMI } \\
2012 \\
n=2065\end{array}$ & $\begin{array}{l}\text { Intracoronary vs intravenous } \\
\text { abciximab in STEMI }\end{array}$ & $\begin{array}{l}\text { No statistical difference in primary end point of } \\
\text { death or MI }\end{array}$ & [50] \\
\hline
\end{tabular}

Table I. Findings of the main studies

\section{Current guidelines for the use of glycoprotein IIb/IIla inhibitors}

\section{ACC/AHA 2009 updated guidelines for STEMI}

The focused update of the ACC/AHA guidelines for management of STEMI from 2004 [51] acknowledged the lack of data with regards to the ongoing use of GP IIb/IIIa inhibitors with dual oral antiplatelet therapy and also newer anticoagulants such as bivalirudin. It was concluded that the role of GP IIb/IIIa inhibitors in current management needs further investigation and admitted the difficulty in drawing definitive conclusions with regards to their ongoing role in the management of STEMI.

The ACC/AHA guidelines state that treatment with abciximab (level of evidence: A) at the time of primary PCI in selected patients with STEMI is reasonable regardless of whether stent insertion is performed. This was classified as a Class IIa recommendation.

These guidelines go on to say that benefit in the use of GP IIb/IIIa inhibitors prior to cardiac catheterisation laboratory remains uncertain due to the lack of supporting evidence (level of evidence: B, class IIb).

\section{ESC guidelines for STEMI 2012}

Due to the recent prominence of direct thrombin inhibitor use in European centres the updated ESC guidelines heavily featured bivalirudin in the management of STEMI with subsequent further downgrading of the role of GP IIb/IIIa inhibitors [52]. A significant change was the class 1c recommendation that an injectable anticoagulant must be used during STEMI and that bivalirudin is now indicated over the combination use of heparin and GP IIb/IIIa inhibitor. This recommendation was based on the aforementioned recent data showing non-inferiority of bivalirudin and decreased rates of significant bleeding and mortality. 


\section{Recommendations}

$\begin{array}{ll}\text { STEMI } & \text { Class IIa: GP IIb/IIIa inhibitors are reasonable for use in PCI with unfractionated heparin whether } \\ \text { the patient has received pre-treatment with clopidogrel (Level of evidence: B) or no dual antiplatelet } \\ \text { therapy (Level of evidence: A) } \\ \text { - Class IIb: It is reasonable to use intracoronary abciximab during PCI though not specifically } \\ \text { recommended (Level of evidence: B) } \\ \text { - Class III: Routine use of upstream GP IIb/IIla inhibitors (i.e. prior to cardiac catheter laboratory) is not } \\ \text { beneficial (Level of evidence: B) } \\ \text { - Class I: GP IIb/IIla inhibitors are useful in conjunction with unfractionated heparin in those patients } \\ \text { undergoing PCI with high risk features (e.g. elevated troponin level) that have not received bivalirudin } \\ \text { or adequately pre-treated with clopidogrel (Level of evidence: A) } \\ \text { - Class Ila: GP IIb/IIIa inhibitors are reasonable at the time of PCI in UA/NSTEMI patients with high risk } \\ \text { features who have been adequately pre-treated with clopidogrel (Level of evidence: B) } \\ \text { - Class IIa: GP IIb/IIla inhibitors are reasonable for use during PCI in conjunction with unfractionated } \\ \text { heparin in those patients not pre-treated with clopidogrel (Level of evidence: B) } \\ \text { - Class IIb: In patients receiving elective PCI with stent insertion the use of GP IIb/IIla inhibitors might } \\ \text { be reasonable in conjunction with unfractionated heparin and pre-treatment with clopidogrel (Level } \\ \text { of evidence: B) }\end{array}$

Table II. Recomendandations of current guidelines

GP IIb/IIIa inhibitors remain a therapeutic option to be considered for bailout therapy if there should be angiographic evidence of massive thrombus, slow or no-reflow or a thrombotic complication (IIa, level of evidence: C). It is stated that this indication is only as a recommendation as little data is available for this specific use and there is need for further randomised control studies.

Upstream use of GP IIb/IIIa inhibitors was only recommended for consideration in high-risk patients as bridging therapy towards primary PCI (IIb, level of evidence: B).

\section{ACCF/AHA/SCAI guideline for percutaneous coronary intervention}

The guidelines from the Society for Cardiovascular Angiography and Interventions (SCAI) have detailed accounts of the efficacy and usefulness of GP IIb/IIIa inhibitors not only in STEMI but also unstable angina (UA), NSTEMI and stable ischaemic heart disease [53].

Their recommendations are summarized in Table II.

\section{Conclusion}

Abciximab is a glycoprotein IIb/IIIa inhibitor with numerous early trials that demonstrated its significant efficacy in the treatment of STEMI, NSTEMI and unstable angina. Its use has been proven beneficial in the setting of coronary intervention. It is a potent antiplatelet agent that is capable of complete inhibition of platelet aggregation. Its use carries an increased risk of bleeding but if used with caution in carefully selected patient groups this risk could be kept very low.

A common and potentially dangerous complication of abciximab therapy is drug-induced thrombocytopaenia, which may lead to significant adverse outcomes.

Data suggests the best time of administration is at the time of PCI and there is no clear benefit of administration via the intracoronary route or in conjunction with thrombolysis. Abciximab should be used in caution in patients that may be candidates for emergency CABG. 
Future research question

The cutting edge of cardiology is in the genetics and genomics. It is important to study whether genetic testing would provide important information on who would benefit the most from abciximab therapy in the context of acute coronary syndrome. The future acute cardiovascular therapeutics need to be tailored according to the genetic risk markers and indicators
Early trials in its use pre-date the advent of dual oral antiplatelet therapy with aspirin and a thienopyridine agent and thus abciximab and its fellow GP IIb/IIIa inhibitors now have a scaled down role in current guidelines due to the lack of evidence for additional benefit with these agents. With the introduction of new anticoagulant agents with improved safety profiles (such as bivalirudin) we may soon see further relegation of these drugs to use as bailout therapy with PCI only.

The review in brief

Clinical question This review attempts to study the cross-section of the evidence base to date on the clinical use, efficacy and risks related to the use of abciximab and spotlight the most recent guidelines published by the different global peak bodies to provide a practical overview to the clinician

Type of review Narrative

Search of the PubMed with follwing keywords: Abciximab, Antiplatelet agents, Acute coronary syndrome

literature

Conclusions Numerous trials demonstrated significant efficacy of abciximab in the treatment of STEMI, NSTEMI and unstable angina. Its use has been proven beneficial in the setting of coronary intervention. It is a potent antiplatelet agent that is capable of complete inhibition of platelet aggregation

Limitations There have been significant advancements in interventional technology, oral antiplatelet agents and intravenous anticoagulants since the pivotal trials that proved the benefits of abciximab. The lack of a large evidence base on how beneficial abciximab is in the context of modern interventional technologies and pharmacotheraputics for the management of ACS compromises the practical value of the review. More trials and the analyses of registry data are required to address this issue in relation to the best use of abciximab in the modern context

\section{References}

1. Hashemzadeh M, Furukawa M, Goldsberry S, et al. Chemical structures and mode of action of intravenous glycoprotein IIb/IIIa receptor blockers: a review. Exp Clin Cardiol 2008; 12: 192-7

2. Schrör K, Weber A. Comparative pharmacology of GP IIb/IIIa antagonists. J Thromb Thrombolys 2003;15: 71-80; http://dx.doi.org/10.1023/B:THRO.0000003308.63022.8d

3. Darius H. Oral glycoprotein IIb/IIIa antagonists for unstable angina - Is there still a chance for the oral substances? Thromb Res 2001;103: 117-24; http://dx.doi.org/10.1016/S0049-3848(01)00308-5

4. Califf RM, Lincoff AM, Tcheng JE, et al. An overview of the results of the EPIC trial. Eur Heart J 1995; 16 (Supp L): 43-9; http://dx.doi.org/10.1093/eurheartj/16.suppl_L.43

5. Adgey AA. An overview of the results of clinical trials with glycoprotein IIb/IIIa inhibitors. Euro Heart J 1998; 19 Suppl D: D10-21

6. Ghaffari S, Kereiakes DJ, Lincoff AM, et al. Platelet glycoprotein IIb/IIIa receptor blockade with abciximab reduces ischemic complications in patients undergoing directional coronary atherectomy. EPILOG Investigators. Evaluation of PTCA to Improve Long-term Outcome by c7E3 
GP IIb/IIIa Receptor Blockade. Am J Cardiol 1998; 82: 7-12; http://dx.doi.org/10.1016/S00029149(98)00238-0

7. Topol E; The EPISTENT Investigators. Randomised placebo-controlled and balloon-angioplasty-controlled trial to assess safety of coronary stenting with use of platelet glycoprotein-IIb/IIIa blockade. The Lancet 1998; 352: 87-92; http://dx.doi.org/10.1016/S0140-6736(98)85010-1

8. CAPTURE investigators. Randomised placebo-controlled trial of abciximab before and during coronary intervention in refractory unstable angina: the CAPTURE trial. The Lancet 1997; 349: 1429-35; http://dx.doi.org/10.1016/S0140-6736(96)10452-9

9. De Luca G, Suryapranata H, Stone GW, et al. Abciximab as adjunctive therapy to reperfusion in acute ST-segment elevation myocardial infarction: a meta-analysis of randomized trials. JAMA 2005; 293: 1759; http://dx.doi.org/10.1001/jama.293.14.1759

10. Sabatine MS, Jang IK. The use of glycoprotein IIb/IIIa inhibitors in patients with coronary artery disease. Am J Med 2000; 109: 224; http://dx.doi.org/10.1016/S0002-9343(00)00474-5

11. Mehilli J, Kastrati A, Schulz S, et al. Abciximab in patients with acute ST-segment-elevation myocardial infarction undergoing primary percutaneous coronary intervention after clopidogrel loading. Circulation 2009; 119: 1933-40; http://dx.doi.org/10.1161/CIRCULATIONAHA.108.818617

12. The GUSTO V Investigators. Reperfusion therapy for acute myocardial infarction with fibrinolytic therapy or combination reduced fibrinolytic therapy and platelet glycoprotein IIb/IIIa inhibition: the GUSTO V randomised trial. The Lancet 2001; 357: 1905-14; http://dx.doi.org/10.1016/S01406736(00)05059-5

13. The ASSENT 3 Investigators. Efficacy and safety of tenecteplase in combination with enoxaparin, abciximab, or unfractionated heparin: the ASSENT 3 randomised trial in acute myocardial infarction. The Lancet 2001; 358: 605-13; http://dx.doi.org/10.1016/S0140-6736(01)05775-0

14. Ellis SG, Tendera M, de Belder MA, et al. Facilitated PCI in patients with ST-elevation myocardial infarction. N Engl J Med 2008; 358: 2205; http://dx.doi.org/10.1056/NEJMoa0706816

15. Sane DC, Damaraju LV, Topol EJ, et al. Occurrence and clinical significance of pseudothrombocytopenia during abciximab therapy. J Am Coll Cardiol 2000; 36: 75; http://dx.doi.org/10.1016/ S0735-1097(00)00688-4

16. Berkowitz SD, Harrington RA, Rund MM, et al. Acute profound thrombocytopenia after C7E3 Fab (abciximab) therapy. Circulation 1997; 95: 809; http://dx.doi.org/10.1161/01.CIR.95.4.809

17. Berkowitz SD, Sane DC, Sigmon KN, et al. Occurrence and clinical significance of thrombocytopenia in a population undergoing high-risk percutaneous coronary revascularization. Evaluation of c7E3 for the Prevention of Ischemic Complications (EPIC) Study Group. J Am Coll Cardiol 1998; 32: 311; http://dx.doi.org/10.1016/S0735-1097(98)00252-6

18. Dasgupta H, Blankenship JC, Wood GC, et al. Thrombocytopenia complicating treatment with intravenous glycoprotein IIb/IIIa receptor inhibitors: a pooled analysis. Am Heart J 2000; 140: 206; http://dx.doi.org/10.1067/mhj.2000.107554

19. Merlini PA, Rossi M, Menozzi A, et al. Thrombocytopenia caused by abciximab or tirofiban and its association with clinical outcome in patients undergoing coronary stenting. Circulation 2004; 109: 2203; http://dx.doi.org/10.1161/01.CIR.0000127867.41621.85

20. Warkentin TE. Think of HIT. Hematology Am Soc Hematol Educ Program, 2006; http://dx.doi. org/10.1182/asheducation-2006.1.408

21. Curtis BR, Swyers J, Divgi A, et al. Thrombocytopenia after second exposure to abciximab is caused by antibodies that recognize abciximab-coated platelets. Blood 2002; 99: 2054; http://dx.doi. org/10.1182/blood.V99.6.2054

22. Tcheng JE, Kereiakes DJ, Lincoff AM, et al. Abciximab readministration: results of the ReoPro Readministration Registry. Circulation 2001; 104: 870; http://dx.doi.org/10.1161/hc3301.094533 
23. Madan M, Kereiakes DJ, Hermiller JB, et al. Efficacy of abciximab readministration in coronary intervention. Am J Cardiol 2000; 85: 435; http://dx.doi.org/10.1016/S0002-9149(99)00768-7

24. Lincoff AM, Tcheng JE, Califf RM, et al. Sustained suppression of ischemic complications of coronary intervention by platelet GP IIb/IIIa blockade with abciximab: one-year outcome in the EPILOG trial. Evaluation in PTCA to Improve Long-term Outcome with abciximab GP IIb/IIIa blockade. Circulation 1999; 99: 1951; http://dx.doi.org/10.1161/01.CIR.99.15.1951

25. Brener SJ, Barr LA, Burchenal JE, et al. Randomized, placebo-controlled trial of platelet glycoprotein IIb/IIIa blockade with primary angioplasty for acute myocardial infarction. ReoPro and Primary PTCA Organization and Randomized Trial (RAPPORT) Investigators. Circulation 1998; 98: 734; http://dx.doi.org/10.1161/01.CIR.98.8.734

26. Harrington RA, Kleiman NS, Kottke-Marchant K, et al. Immediate and reversible platelet inhibition after intravenous administration of a peptide glycoprotein IIb/IIIa inhibitor during percutaneous coronary intervention. Am J Cardiol 1995; 76: 1222; http://dx.doi.org/10.1016/S00029149(99)80345-2

27. The IMPACT-II Investigators. Randomised placebo-controlled trial of effect of eptifibatide on complications of percutaneous coronary intervention: IMPACT-II. Integrilin to Minimise Platelet Aggregation and Coronary Thrombosis-II. The Lancet 1997; 349: 1422; http://dx.doi.org/10.1016/ S0140-6736(96)10172-0

28. The PURSUIT Trial Investigators. Inhibition of platelet glycoprotein IIb/IIIa with eptifibatide in patients with acute coronary syndromes. Platelet Glycoprotein IIb/IIIa in Unstable Angina: Receptor Suppression Using Integrilin Therapy. N Engl J Med 1998; 339: 436; http://dx.doi.org/10.1056/ NEJM199808133390704

29. Kastrati A, Mehilli J, Neumann FJ, et al. Abciximab in patients with acute coronary syndromes undergoing percutaneous coronary intervention after clopidogrel pretreatment: the ISAR-REACT 2 randomized trial. JAMA 2006; 295: 1531; http://dx.doi.org/10.1001/jama.295.13.joc60034

30. Memon MA, Blankenship JC, Wood GC, et al. Incidence of intracranial hemorrhage complicating treatment with glycoprotein IIb/IIIa receptor inhibitors: a pooled analysis of major clinical trials. Am J Med 2000; 109: 213; http://dx.doi.org/10.1016/S0002-9343(00)00453-8

31. Dyke CM. Safety of glycoprotein IIb/IIIa inhibitors: a heart surgeon's perspective. Am Heart J 1999; 138: 307-16; http://dx.doi.org/10.1053/hj.1999.v138.a100460

32. Boehrer JD, Kereiakes DJ, Navetta FI, et al. Effects of profound platelet inhibition with c7E3 before coronary angioplasty on complications of coronary bypass surgery. Am J Cardiol 1994; 74: 116670; http://dx.doi.org/10.1016/0002-9149(94)90474-X

33. Aguirre FV, Topol EJ, Ferguson JJ, et al. Bleeding complications with the chimeric antibody to platelet glycoprotein IIb/IIIa integrin in patients undergoing percutaneous coronary intervention. Circulation 1995; 91 :2882-90; http://dx.doi.org/10.1161/01.CIR.91.12.2882

34. Booth JA, Patel VB, Balog C, et al. Is bleeding risk increased in patients undergoing urgent coronary bypass surgery following abciximab? Circulation 1998; 98(Suppl): 845

35. Bracey A, Radovancevic R, Vaugh W, et al. Blood use in emergency coronary artery bypass after receipt of abciximab during angioplasty. Transfusion 1998: S250

36. Alvarez J.M. Emergency coronary bypass grafting for failed percutaneous coronary artery stenting. J Thorac Cardiovasc Surg 1998; 115: 472-3; http://dx.doi.org/10.1016/S0022-5223(98)70296-X

37. Akerblom A, James SK, Koutouzis M, et al. Eptifibatide is noninferior to abciximab in primary percutaneous coronary intervention: results from the SCAAR (Swedish Coronary Angiography and Angioplasty Registry). J Am Coll Cardiol 2010; 56: 470-5

38. Zeymer U, Margenet A, Haude M, et al. Randomized comparison of eptifibatide versus abciximab in primary percutaneous coronary intervention in patients with acute ST-segment elevation myo- 
cardial infarction: results of the EVA-AMI Trial. J Am Coll Cardiol 2010; 56: 463-9; http://dx.doi. org/10.1016/j.jacc.2009.08.093

39. Gurm H, Tamhane U, Meier P, et al. A comparison of abciximab and small molecule glycoprotein IIb/IIIa inhibitors in patients undergoing primary percutaneous coronary intervention: a metaanalysis of contemporary randomized controlled trials. Circ Cardiovasc Intervent 2009; 2: 230-6; http://dx.doi.org/10.1161/CIRCINTERVENTIONS.108.847996

40. De Luca G, Ucci G, Cassetti E, et al. Benefits from small molecule administration as compared with abciximab among patients with ST-segment elevation myocardial infarction treated with primary angioplasty: a meta-analysis. J Am Coll Cardiol 2009; 53: 1668-73; http://dx.doi.org/10.1016/j. jacc.2009.01.053

41. Dangas GD, Lansky AJ, Brodie BR. Predictors of Stent Thrombosis After Primary Angioplasty in Acute Myocardial Infarction: The HORIZONS-AMI Trial; http://www.cardiosource.com/rapidnewssummaries/summary.asp?SumID=406

42. Jayasinghe R, Yudi M, Jayasinghe S. Comparative efficacy of eptifibatide and abciximab in primary angioplasty study. Research Reports in Clinical Cardiology 2011: 2: 7-13; DOI. 10.2147/ RRCC,S16471

43. Stone, GW, Witzenbichler B, Guagliumi G, et al. Bivalirudin during primary PCI in acute myocardial infarction. N Engl J Med 2008; 358: 2218-30; http://dx.doi.org/10.1056/NEJMoa0708191

44. Mehran R, Lansky AJ, Witzenbichler B, et al. Bivalirudin in patients undergoing primary angioplasty for acute myocardial infarction (HORIZONS-AMI): 1-year results of a randomised controlled trial. The Lancet 2009; 374: 1149-59; http://dx.doi.org/10.1016/S0140-6736(09)61484-7

45. Kushner F, Hand M, Smith S, et al. 2009 Focused Updates: ACC/AHA Guidelines for the Management of Patients with ST-elevation Myocardial Infarction (Updating the 2004 Guideline and 2007 Focused Update) and ACC/AHA/SCAI Guidelines on Percutaneous Coronary Intervention (Updating the 2005 Guideline and 2007 Focused Update). J Am Coll Cardiol 2009; 54: 2205-41; http://dx.doi.org/10.1016/j.jacc.2009.10.015 